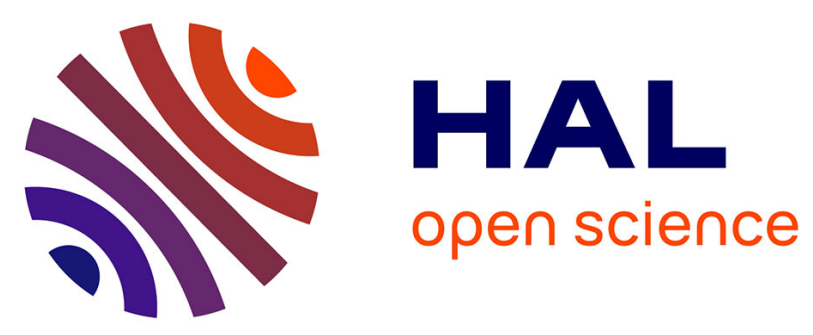

\title{
Influence of the Dengue Serotype, Previous Dengue Infection, and Plasma Viral Load on Clinical Presentation and Outcome During a Dengue-2 and Dengue-4 Co-Epidemic
}

Laurent Thomas, Olivier Verlaeten, André Cabié, Stéphane Kaidomar, Victor Moravie, Jenny Martial, Fatiha Najioullah, Yves Plumelle, Christiane Fonteau, Philippe Dussart, et al.

\section{- To cite this version:}

Laurent Thomas, Olivier Verlaeten, André Cabié, Stéphane Kaidomar, Victor Moravie, et al.. Influence of the Dengue Serotype, Previous Dengue Infection, and Plasma Viral Load on Clinical Presentation and Outcome During a Dengue-2 and Dengue-4 Co-Epidemic. American Journal of Tropical Medicine and Hygiene, 2008, 78 (6), pp.990-998. 10.4269/ajtmh.2008.78.990 . pasteur-03214523

\section{HAL Id: pasteur-03214523}

https://hal-riip.archives-ouvertes.fr/pasteur-03214523

Submitted on 1 May 2021

HAL is a multi-disciplinary open access archive for the deposit and dissemination of scientific research documents, whether they are published or not. The documents may come from teaching and research institutions in France or abroad, or from public or private research centers.
L'archive ouverte pluridisciplinaire HAL, est destinée au dépôt et à la diffusion de documents scientifiques de niveau recherche, publiés ou non, émanant des établissements d'enseignement et de recherche français ou étrangers, des laboratoires publics ou privés.

$$
\text { Copyright }
$$




\title{
Influence of the Dengue Serotype, Previous Dengue Infection, and Plasma Viral Load on Clinical Presentation and Outcome During a Dengue-2 and Dengue-4 Co-Epidemic
}

\author{
Laurent Thomas,* Olivier Verlaeten, André Cabié, Stéphane Kaidomar, Victor Moravie, Jenny Martial, \\ Fatiha Najioullah, Yves Plumelle, Christiane Fonteau, Philippe Dussart, and Raymond Césaire \\ Centre Hospitalier Universitaire, Fort-de-France, Martinique; Centre d'Investigation Clinique et d'Epidémiologie Clinique, \\ Fort-de-France, Martinique; Centre National de Référence des Arbovirus, Institut Pasteur de la Guyane, Cayenne, French Guyana
}

\begin{abstract}
Martinique experienced a dengue outbreak with co-circulation of DENV-2 and DENV-4. In an emergency department-based study, we analyzed whether the clinical presentation and outcome of adult patients were related to serotype, immune status, or plasma viral load. Of the 146 adult patients who had confirmed dengue infection, 91 (62.3\%) were classified as having classic dengue fever, 11 (7.5\%) fulfilled World Health Organization criteria for dengue hemorrhagic fever (DHF) or dengue shock syndrome (DSS), 21 other patients (14.4\%) presented with at least one typical feature of DHF/DSS [i.e., internal hemorrhage, plasma leakage, marked thrombocytopenia (platelet count $\leq$ 50,000 platelets $\left./ \mathrm{mm}^{3}\right)$ and/or shock], and 23 further patients $(15.8 \%)$ had unusual manifestations. Four patients died. Severe illness was more frequent in patients with secondary dengue infection (odds ratio, 7.18; $95 \%$ confidence interval, 3.1-16.7; $P<0.001$ ). Multivariate regression analysis showed that gastrointestinal symptoms and other unusual manifestations were independently associated with DENV-2 infection, whereas cough and DHF/DSS features were independently associated with secondary immune response. A high plasma viral load was associated with DENV-2 infection, increased serum liver enzymes, and with DHF/DSS features in patients presenting after the third day of illness. The most severe cases of dengue resulted from the combined effects of DENV-2 and secondary infection.
\end{abstract}

\section{INTRODUCTION}

Dengue viruses are classified into four antigenically distinct serotypes designated DENV-1 to DENV-4. Although most infections are asymptomatic, all four DENV serotypes can cause a spectrum of disease ranging from "flu-like illness" [dengue fever (DF)] to life-threatening dengue hemorrhagic fever (DHF) and dengue shock syndrome (DSS). ${ }^{1}$ The pathophysiology of severe dengue disease seems to be multifactorial, involving interactions between viral characteristics, immune features, and host genetic background. ${ }^{2-5}$ Hyperendemicity with multiple serotypes is believed to be one of the most significant factors influencing dengue severity. ${ }^{3-6}$

Martinique is a Windward Island of the Caribbean. It is an overseas department of France of $1,128 \mathrm{~km}^{2}$ with a population of $\sim 400,000$ inhabitants. Its "Creole" population is the result of mixing European and African ancestry over five centuries. During the 19th century, Indian and to a lesser extent Chinese migrants arrived in the country, and they integrated rapidly.

During the last decade, Martinique has experienced four dengue epidemics caused by DENV-2 and DENV-4 in 1995, DENV-1 in 1997, and DENV-3 in 2001. ${ }^{7}$ Molecular epidemiologic surveillance showed that DENV-2 has persisted, whereas DENV-4 re-emerged in 2004 after a 9-year absence. The re-emerging DENV-4 clade in the French West Indies is phylogenetically related to subtype II strains isolated in the Bahamas in $1998,{ }^{8}$ whereas the DENV-2 clade is closely related to subtype III (Asian-American subtype). ${ }^{9}$

The dengue surveillance network counted $\sim 14,500$ cases of dengue fever between June 2005 and April 2006. ${ }^{7}$ The outbreak was characterized by co-circulation of DENV-2 and DENV-4. Here we report data on adult victims. Particular attention was paid to clinical severity in view of recent developments. ${ }^{10,11}$ The outcome was analyzed according to the

\footnotetext{
* Address correspondence to Laurent Thomas, Service des Urgences, Centre Hospitalier Universitaire, 97200 Fort-de-France, Martinique. E-mail: laurent.thomas@chu-fortdefrance.fr
}

dengue serotype, pre-existing heterologous antibodies, and plasma viral load.

\section{MATERIALS AND METHODS}

Study participants. The Emergency Department for adults is part of the dengue surveillance network in Martinique and focuses on early detection of severe clinical forms. All patients at least 15 years of age, with a history of acute febrile illness, admitted within 8 days of onset of fever between June 2005 and April 2006, were eligible for inclusion in this study with their informed consent. Information about patients' ethnicity was not reported because of the current strict medical ethics laws in France. Clinical data were recorded at the bedside with a computerized medical record system and a questionnaire tailored to acute febrile illness. Routine laboratory tests were performed. In addition, a $10-\mathrm{mL}$ serum sample was stored in aliquots at $-70^{\circ} \mathrm{C}$ for remote immunologic and virologic studies. All patients in whom dengue infection was shown by reverse transcriptase-polymerase chain reaction (RT-PCR) and/or anti-dengue immunoglobulin M (IgM) detection were included in the study. A daily clinical evaluation and repeated laboratory tests were performed on all hospitalized patients. Follow-up data after the first visit and triage were obtained from the medical records and/or personal phone calls after discharge.

Case definitions. Clinical forms were classified retrospectively, based on data recorded at the first visit and during follow-up. DHF and DSS were diagnosed according to the World Health Organization (WHO) classification system. ${ }^{1}$ In keeping with earlier studies, ${ }^{12-14}$ patients who presented with at least one typical feature of DHF/DSS [i.e., internal hemorrhage or signs consistent with plasma leakage (hematocrit $>50 \%$, proteinemia $<50 \mathrm{~g} / \mathrm{L}$, and/or clinical evidence of serous effusion in the pleural or peritoneal cavity), marked thrombocytopenia $\left(<50 \times 10^{9}\right.$ platelets/L), or shock (delayed capillary refill, systolic pressure $<90 \mathrm{~mm}$ of $\mathrm{Hg}$ and/or pulse pressure $\leq 20 \mathrm{~mm}$ of $\mathrm{Hg}$ )], were also included in a "DHF/ DSS-like" group (Table 1). As recently proposed, ${ }^{11}$ an "unusual manifestations" group was also created, made up of 
TABLE 1

Clinical criteria used for retrospective classification of patients with confirmed dengue fever in Martinique

\begin{tabular}{|c|c|c|}
\hline Signs and symptoms & $N=146$ & Clinical forms of severity \\
\hline $\begin{array}{l}\text { Acute febrile illness with at least two of the following: headache, } \\
\text { myalgia, vomiting, abdominal pain, asthenia. No bleeding or } \\
\text { mild external spontaneous bleeding or positive tourniquet test. } \\
\text { No apparent plasma leakage. Platelet counts }>50 \times 10^{9} / \mathrm{L}\end{array}$ & 91 & $\begin{array}{l}\text { Classic DF } \\
\qquad(N=91,62.3 \% \text { of patients })\end{array}$ \\
\hline \multicolumn{3}{|l|}{ Above clinical features and at least one of the following } \\
\hline Symptomatic orthostatic hypotension & 11 & \\
\hline Hepatitis & 6 & \\
\hline Rhabdomyolysis & 3 & \\
\hline Encephalopathy & 5 & Unusual manifestations group \\
\hline Myocarditis & 1 & \\
\hline Pericarditis & 1 & $(N=23,15.8 \%$ of patients $)$ \\
\hline \multicolumn{3}{|c|}{$\begin{array}{l}\text { Above signs and symptoms of DF with or without unusual manifestations, } \\
\text { and at least one of the following: internal hemorrhage, evidence of } \\
\text { plasma leakage, platelet counts }<50 \times 10^{9} / \mathrm{L} \text {, shock }\end{array}$} \\
\hline DHF according to strict WHO requirements & 9 & DHF/DSS-like group \\
\hline DSS according to strict WHO requirements & 2 & $(N=32,21.9 \%$ of patients $)$ \\
\hline Platelet counts $<50 \times 10^{9} / \mathrm{L}$ only & 6 & \\
\hline Miscellaneous overlapping symptoms & 15 & \\
\hline
\end{tabular}

patients not meeting the above DHF/DSS-like criteria but having at least one of the following features: encephalopathy, symptomatic postural hypotension, dehydration, serum electrolyte or acid-base disorders, hepatitis (10-fold increase in aminotransaminases), rhabdomyolysis (20-fold increase in creatine kinase), or elevated cardiac enzymes (troponin-1c $>1 \mu \mathrm{g} / \mathrm{L})$. Patients included in the DHF/DSS-like and unusual manifestations groups were considered to have severe illness. Patients who presented with acute febrile illness alone or associated with isolated mild external hemorrhage (positive tourniquet test, petechiae, mucosal bleeding) were diagnosed as having classic DF.

Dengue RNA detection and genotyping. RT-PCR determination was performed on material sampled on admission to the emergency room. Viral RNA was extracted from $140 \mu \mathrm{L}$ of serum using the High Pure Viral Nucleic Acid reagent set (Roche Molecular Biochemicals, Meylan, France) according to the manufacturer's instructions. RT-PCR was carried out with dengue consensus primers D1 and D2, followed by seminested PCR with D1 and serotype-specific primers TS1, TS2, TS3, and TS4, as described by Lanciotti and others. ${ }^{15}$ This procedure was verified through participation in a multicenter quality control study conducted by the National Reference Center for Arboviruses, Institut Pasteur, French Guiana.

Preparation of dengue virus-titrated controls. Local isolates of DENV-2 and DENV-4 were propagated in Aedes pseudoscutellaris (AP61) cells. The culture supernatants were titrated on vero cell monolayers using a standard plaqueforming assay. Stock suspensions of the two dengue virus serotypes were stored at $-80^{\circ} \mathrm{C}$ until use. Tenfold serial dilutions were made in negative human plasma to obtain concentrations ranging from $10^{6}$ to 10 plaque forming units (PFU)/mL.

Dengue plasma viral load measurement. Quantitative realtime PCR was carried out in sera collected on admission to the emergency room using primers D1 and D2 and intercalation of SYBR Green I as the fluorescence reporter (Verlaeten and others, unpublished data). Briefly, RNA was reverse-transcribed with the SuperScript II Reverse Transcriptase kit (Invitrogen, Cergy-Pontoise, France). Real-time PCR was performed with the iQ SYBR Green Supermix kit (Bio-Rad, Marne la Coquette, France) using the iCycler iQ
Real Time PCR detection system (Bio-Rad). Threshold cycles $\left(C_{T}\right)$ were calculated, and melting curve analysis was done for each PCR product. Standard curves were obtained with titrated DENV-2 and DENV-4 supernatants serially diluted from $10^{6}$ to $10 \mathrm{PFU} / \mathrm{mL}$. The standard curves obtained by serial dilution of titrated DENV-2 and DENV-4 supernatants had similar slopes, the PCR efficiencies being consistently above $90 \%$ and the correlation coefficients $R^{2}>0.997$. The detection limit was estimated at $10 \mathrm{PFU}$ equivalents $/ \mathrm{mL}$.

Antibody responses. Dengue-specific antibodies were detected in sera collected on admission to the emergency room by using IgM capture, IgG capture, and IgG indirect ELISA kits (Panbio, Brisbane, Australia). A serum-to-calibrator absorbance ratio $\geq 1.1$ was defined as positive for $\operatorname{IgM}$ capture and $\mathrm{IgG}$ indirect tests, whereas a ratio $\geq 2.2$ was needed for $\mathrm{IgG}$ capture, as recommended by the manufacturer. The elevated cut-off for the IgG capture test has been shown to discriminate between primary and secondary $\mathrm{IgG}$ responses in a single acute phase serum sample. ${ }^{16,17}$ A positive IgG capture test on serum collected within 7 days of the onset of fever was considered to indicate a secondary infection. Sera negative by IgG capture were tested by the IgG indirect ELISA. If this was positive, the case was also classified as a secondary infection. If both tests were negative, the infection was diagnosed as primary.

Statistical analysis. Data were analyzed using StatView 4.5. Duration of illness at admission was defined as the time elapsed from the date and hour of onset of chills and fever to the date and hour of clinical examination and blood sampling. Each time period from 0 to 24 hours was rounded up to 1 day of illness. Values, where indicated, are expressed as the median and 25-75\% interquartile range (25-75 IR). Data were compared across groups using non-parametric tests. Multiple logistic regression analysis was used to assess whether independent association could be shown between variables of clinical interest and serotype and/or immune status. Odds ratios (ORs) were generated and expressed with 95\% CIs. Twotailed $P \leq 0.05$ was considered statistically significant.

\section{RESULTS}

Spectrum of disease. A total of 389 questionnaires were completed. Of these, 175 (45\%) were assigned alternative 
diagnoses, $68(17.5 \%)$ to indeterminate serologies, and 146 $(37.5 \%)$ to confirmed dengue infections. DENV-2 was shown in 39 patients, DENV-4 in 64 patients, DENV-3 in 6 patients, and DENV-1 in 1 patient. No dual infections were observed. In another 36 patients, the diagnosis of dengue fever was based on a positive IgM capture test only. The median age of the patients with dengue fever was 35 years (25-75 IR, 26 years). There were 63 males and 83 females (female to male ratio 1.3). Most patients (115/146) had been given various doses of paracetamol at home (median maximum dose, 30 $\mathrm{mg} / \mathrm{kg} / \mathrm{d}$; 25-75 IR, $30 \mathrm{mg} / \mathrm{kg} / \mathrm{d}$ ). Twelve patients had notable associated pathologies. Pregnancy was mentioned in two other patients. After the initial assessment, 97 (66.5\%), 25 (17.1\%), and $24(16.4 \%)$ patients, respectively, were classified in the DF, DHF/DSS-like, and unusual manifestations groups. The median time between onset of fever and the first visit was 3 days (25-75 IR, 4 days) and was 2 (25-75 IR, 3 days), 4 (25-75 IR, 2.5 days), and 6 days (25-75 IR, 3 days) in the DF, unusual manifestations, and DHF/DSS-like groups, respectively $(P<0.001$ by Kruskal-Wallis test).

Patient outcome. After the first evaluation, 68 (46.6\%) of the 146 patients were hospitalized. Ten of the other patients returned to the hospital within 3 days. Of these, seven patients had confirmed DF, but three patients were subsequently hospitalized for symptomatic postural hypotension, hepatitis, and DHF. Among the patients who were hospitalized after initial presentation, three patients initially diagnosed with DF were upgraded during hospitalization: two to the unusual manifestations group and one to the DHF/DSSlike group. Five patients initially diagnosed with unusual manifestations were subsequently included in the DHF/DSSlike group. The final classification of clinical severity is shown in Table 1. Symptomatic postural hypotension was documented in $14.4 \%$ of patients $(47.8 \%$ of patients with unusual manifestations and $31.2 \%$ of those with DHF/DSS-like features). Hepatitis was recorded in $7.5 \%$ of patients $(26.1 \%$ of patients with unusual manifestations and $15.6 \%$ of patients with DHF/DSS-like features). Rhabdomyolysis was recorded in $4.8 \%$ of patients (13\% of patients with unusual manifestations and $12.5 \%$ of patients with DHF/DSS-like features).

Three previously healthy patients infected with DENV-2 virus and included in the DHF/DSS-like group at presentation died within 2 weeks after onset of fever: a 62-year-old woman with intracranial bleeding (platelet count $14 \times 10^{9} / \mathrm{L}$ ) died of irreversible coma; a 53-year-old man with fulminant hepatitis (aspartate aminotransferase, 12,770 U/L; platelet count, $17 \times 10^{9} / \mathrm{L}$; prothrombin time, $11 \%$ of normal) developed hepatic coma and died despite attempted liver transplantation; and a 41-year-old woman with acalculous gangrenous cholecystitis developed Proteus mirabilis septicemia and died of septic shock despite attempted cholecystectomy. In addition, a previously healthy 35-year-old woman was diagnosed with acute severe myocarditis 6 days after onset of fever (EKG abnormalities; troponin-1c $=21.9 \mu \mathrm{g} / \mathrm{L}$; elevated dengue IgM antibodies; no serotype available). She refused heart transplantation and died of cardiogenic shock 2 weeks later. No other fatal cases were recorded by the surveillance network in Martinique.

Differences in severity between primary and secondary dengue infections. Analysis of the immune response indicated a primary dengue infection in 78 patients $(66.7 \%)$ and a secondary infection in 39 patients $(33.3 \%)$. A secondary immune response was significantly associated with severe illnesses (OR, 7.18; 95\% CI, 3.1-16.7; $P<0.001$, Fisher test), and all fatal cases involved secondary infection. Patients with secondary infection were more likely to be hospitalized (OR, 3.38; 95\% CI, 1.5-7.6; $P<0.01$, Fisher test). Cough and gastrointestinal symptoms were more frequent in patients with secondary infection ( $41 \%$ versus $19.2 \%$, respectively, $P=0.02$; $78.9 \%$ versus $41 \%, P<0.001$, Fisher test) and so was purpura (13.5\% versus $1.3 \% ; P<0.05$, Fisher test; Figure 1$)$ and hepatitis $(16.2 \%$ versus $1.3 \% ; P<0.01$, Fisher test). Several biochemical and hematologic parameters recorded at presentation in the emergency room differed between patients with primary and secondary dengue infection (Table 2; Figure 2, A and $\mathrm{B}$ ).

Differences in clinical presentation between primary DENV-2 and DENV-4 infections. Primary infection was diagnosed in 17 of 36 DENV-2 patients $(47.2 \%)$ and 52 of 59 DENV-4 patients $(88.1 \% ; P<0.001$, Fisher test). In these patients, the median time between onset of fever and the first visit was 2 days (25-75 IR, 2 days). This was significantly different from the time of presentation of patients with secondary infections (median time, 4 days; $25-75$ IR, 2 days; $P<$ 0.001, Mann-Whitney test). Sore throat was mentioned in 19 DENV-4 patients $(36.5 \%)$ and in 1 DENV-2 patient $(5.9 \%$; $P=0.015$, Fisher test). Gastrointestinal symptoms were recorded in 11 DENV-2 patients (64.7\%) and in 17 DENV-4 patients $(32.7 \% ; P=0.025$, Fisher test). Unusual manifestations were observed mostly in DENV-2 patients, whereas rates of DHF/DSS-like features were identical in both serotypes (Table 3). Patients with DENV-2 infections showed higher serum creatine kinase and aspartate aminotransferase levels.

Differences in clinical presentation between secondary DENV-2 and DENV-4 infections. The distribution of all variables of clinical interest recorded in the emergency room and the clinical forms of severity observed during follow-up were not significantly different between patients with secondary DENV-2 or DENV-4 infections.

Relationship between the plasma viral load and the serotype. The viral loads in serum ranged from 6 to $461,000 \times 10^{3}$ PFU equivalents $/ \mathrm{mL}$, with a median of $7.16 \times 10^{3} \mathrm{PFU}$ equivalents/mL (25-75 IR, $68.29 \times 10^{3} \mathrm{PFU}$ equivalents $\left./ \mathrm{mL}\right)$, and fell from day 1 to day 6 of illness in both the DENV-2 and DENV-4 groups (Figure 2, C and D). DENV-2-infected patients had higher viral loads than DENV-4-infected patients $\left[32.65 \times 10^{3}\left(25-75 \mathrm{IR}, 396.25 \times 10^{3} \mathrm{PFU}\right.\right.$ equivalents $\left./ \mathrm{mL}\right)$ versus $5.2 \times 10^{3} \mathrm{PFU}$ equivalents/mL $\left(25-75 \mathrm{IR}, 33.22 \times 10^{3}\right.$ PFU equivalents $/ \mathrm{mL}$ ), respectively; $P=0.015$, MannWhitney test]. However, this difference in viral loads between serotypes only held true for primary infections (Table 3).

No correlation was observed between plasma viral load and sex, age, and most physiological variables. A noteworthy exception was that higher viral loads were seen in patients with aspartate aminotransferase levels at least 5-fold the normal value $\left[45.9 \times 10^{3}\left(25-75 \mathrm{IR}, 2,367 \times 10^{3} \mathrm{PFU}\right.\right.$ equivalents $\left./ \mathrm{mL}\right)$ versus $5.8 \times 10^{3} \mathrm{PFU}$ equivalents/mL $\left(25-75 \mathrm{IR}, 47.98 \times 10^{3}\right.$ PFU equivalents $/ \mathrm{mL}$ ), respectively; $P=0.05$, Mann-Whitney test]. The highest plasma viral load $\left(461,000 \times 10^{3} \mathrm{PFU}\right.$ equivalents $/ \mathrm{mL}$ ) was recorded in the patient with secondary DENV-2-associated fatal fulminant hepatitis.

Relationship between the plasma viral load and the immune status. Viral loads were not significantly different be- 


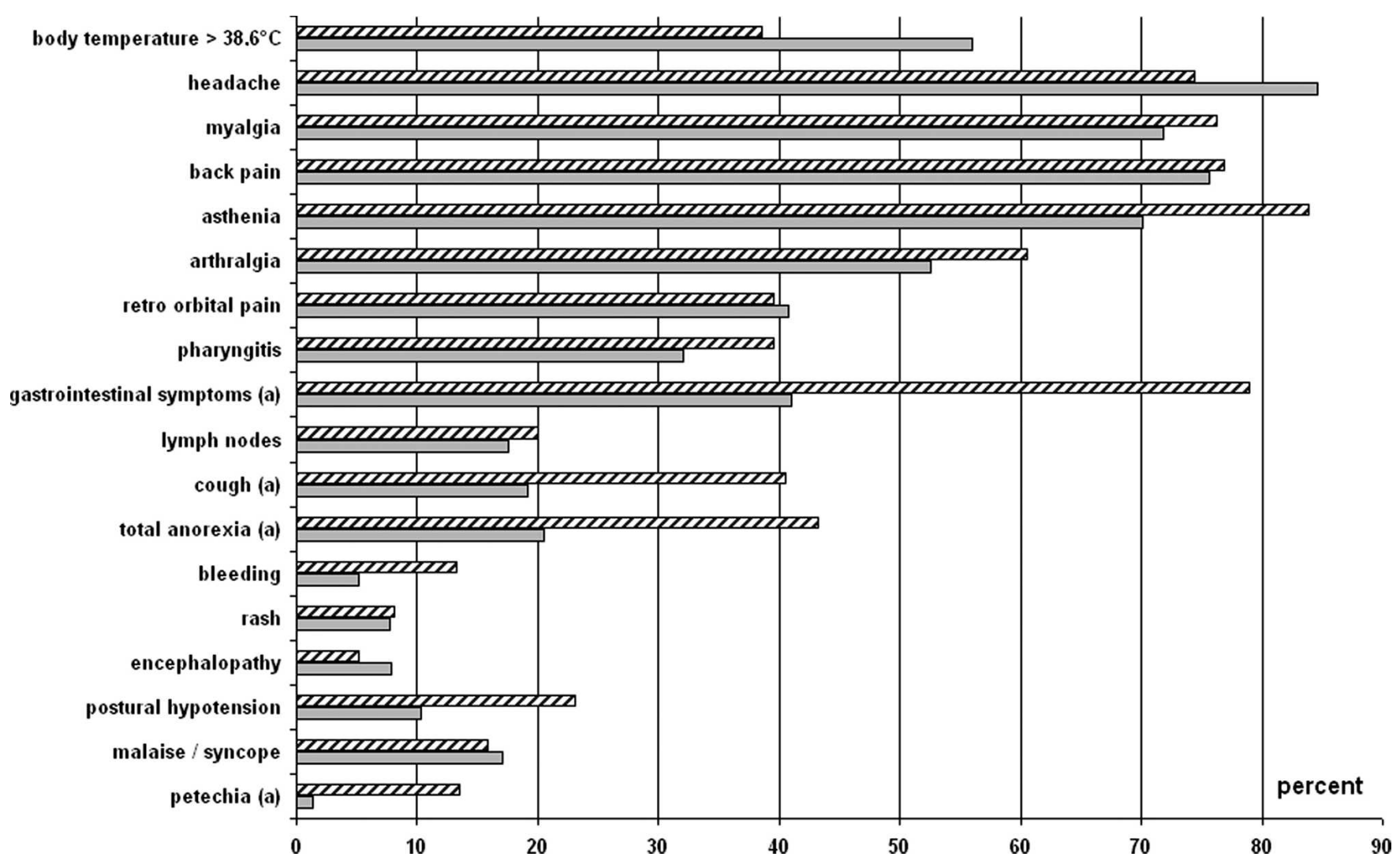

FIGURE 1. Frequency of basic symptoms reported on admission to the emergency room in adult patients diagnosed with primary (gray bars) or secondary dengue infections (hatched bars). (a) $P<0.05$, Fisher test.

TABLE 2

Data recorded on admission to the emergency room and final clinical severity diagnosed during follow-up in patients with confirmed primary or secondary heterologous dengue infections

\begin{tabular}{|c|c|c|c|}
\hline Data* & $\begin{array}{l}\text { Primary infection } \\
\quad(N=78)\end{array}$ & $\begin{array}{l}\text { Secondary dengue infection } \\
\qquad(N=39)\end{array}$ & $P$ \\
\hline Age (years) & $34(27)$ & $35(22)$ & 0.924 \\
\hline Male/female $(N)$ & $32 / 46$ & $21 / 18$ & 0.238 \\
\hline Body temperature $\left({ }^{\circ} \mathrm{C}\right)$ & $38.8(1.3)$ & $37.8(2.5)$ & $0.013 \dagger$ \\
\hline Pulse pressure $(\mathrm{mm}$ of $\mathrm{Hg})$ & $49(22.5)$ & $48.5(16)$ & 0.479 \\
\hline Heart rate (beats/min) & $95(28)$ & $82(14)$ & $0.018 \dagger$ \\
\hline Natremia $(\mathrm{mmol} / \mathrm{L})[135-145] \ddagger$ & $137(4)$ & $135(4)$ & 0.088 \\
\hline Chloremia $(\mathrm{mmol} / \mathrm{L})$ [90-105] & $99(3)$ & $97.5(6)$ & $0.002 \dagger$ \\
\hline Kaliemia $(\mathrm{mmol} / \mathrm{L})[3.5-4.5]$ & $3.9(0.6)$ & $3.9(0.6)$ & 0.318 \\
\hline $\mathrm{HCO}_{3}^{-}(\mathrm{mmol} / \mathrm{L})[22-30]$ & $24(4)$ & $25(4)$ & 0.369 \\
\hline Proteinemia $(\mathrm{g} / \mathrm{L})[60-80]$ & $73(6.8)$ & $72(10.5)$ & 0.477 \\
\hline Hematocrit (\%) $[36-44]$ & $39(6)$ & $41(6.8)$ & $0.005 \dagger$ \\
\hline Hemoglobinemia $(\mathrm{g} / \mathrm{L})$ [105-135] & $132(24)$ & $141(24)$ & $0.001 \dagger$ \\
\hline Platelets $\left(\times 10^{9} / \mathrm{L}\right)[150-350]$ & $168(78.8)$ & $82(97)$ & $<0.001 \dagger$ \\
\hline Polymorphonuclear cells $\left(\times 10^{9} / \mathrm{L}\right)[1.5-8.5]$ & $4.17(2.5)$ & $3.11(2.4)$ & $0.002 \dagger$ \\
\hline Lymphocytes $\left(\times 10^{9} / \mathrm{L}\right)[1-4]$ & $0.56(0.39)$ & $0.83(0.79)$ & $<0.001 \dagger$ \\
\hline $\operatorname{AST}(\mathrm{U} / \mathrm{L})[4-37]$ & $30.5(21)$ & $130(209)$ & $<0.001 \dagger$ \\
\hline $\operatorname{ALT}(\mathrm{U} / \mathrm{L})[4-50]$ & $19(21)$ & $78(155)$ & $<0.001 \dagger$ \\
\hline CK $(\mathrm{U} / \mathrm{L})[20-170]$ & $153(148)$ & $200(364)$ & 0.187 \\
\hline $\mathrm{CRP}(\mathrm{mg} / \mathrm{L})[0-10]$ & $9.6(38.7)$ & $6.6(28)$ & 0.208 \\
\hline APTT(s) $[25-40]$ & $37(3.3)$ & $41.5(7)$ & $0.001 \dagger$ \\
\hline Prothrombin level (\%) [70-100] & $73(17)$ & $82(17)$ & $0.007 \dagger$ \\
\hline Viral load $\left(\times 10^{3}\right.$ PFU equivalent $\left./ \mathrm{mL}\right)$ & $10.7(72.6) N=59$ & $2.5(9.4) N=19$ & 0.23 \\
\hline Classic dengue fever $[N(\%)]$ & $61(78.2)$ & $13(33.3)$ & $<0.001 \S$ \\
\hline DHF/DSS-like group $\mathbb{I}[N(\%)]$ & $4(5.1)$ & $16(41.1)$ & $<0.001 \S$ \\
\hline Unusual manifestations** $[N(\%)]$ & $13(16.7)$ & $10(25.6)$ & 0.32 \\
\hline Hospitalized $[N(\%)]$ & $29(37.2)$ & $26(66.7)$ & $0.003 \S$ \\
\hline
\end{tabular}

* Median value and $(25-75 \%$ interquartile range)

$\dagger P<0.05$ by Mann-Whitney test.

$\ddagger$ Reference range is shown in brackets.

$\S P<0.05$ Fisher's test.

II DHF/DSS-like group was defined as the presence of at least one of the following: internal hemorrhage, signs of plasma leakage, shock, platelet count $<50 \times 10^{9} / \mathrm{L}$

** Unusual manifestations group was made up of other severe clinical manifestations not included in the definition of DHF/DSS-like group.

AST, aspartate aminotransferase; ALT, alanine aminotransferase; CK, creatine kinase; CRP, C reactive protein; APTT, activated partial thromboplastin time; PFU, plaque forming unit. 


\section{Platelet counts $(/ \mathrm{mL})$}
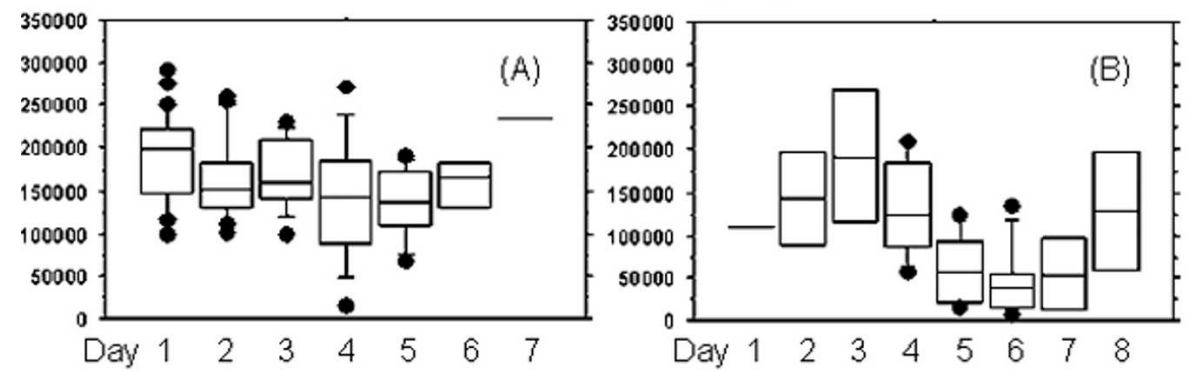

Plasma viral loads (log10 PFU equivalent $/ \mathrm{mL})$
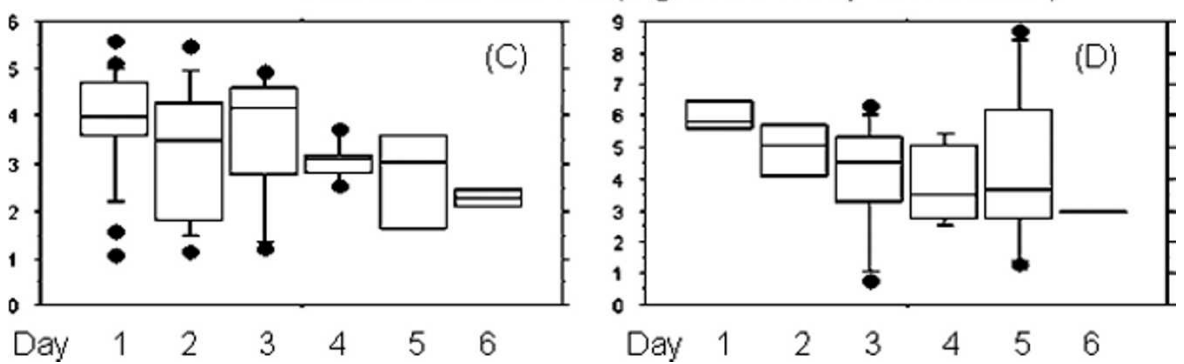

FIGURE 2. Distribution of platelet counts and plasma viral loads recorded on admission to the emergency room according to the time since onset of fever. A, Patients with primary dengue infection $(P=0.01$, Spearman rank correlation test $)$. B, Patients with secondary infection $(P=$ 0.003, Spearman). C, Patients with DENV-4 infections $(P=0.008$, Spearman $)$. D, Patients with DENV-2 infections $(P<0.05$, Spearman $)$. Box plots show median values (horizontal line in the box), $25-75 \%$ interquartile range (lower-upper limits of the box), $90 \%$ range of data (additional bars), and outliers (circles).

TABLE 3

Data recorded on admission to the emergency room and final clinical forms of severity diagnosed during follow-up in patients with confirmed primary dengue DENV-2 or DENV-4 infections

\begin{tabular}{|c|c|c|c|}
\hline Data* & DENV-2 $(N=17)$ & DENV-4 $(N=52)$ & $P$ \\
\hline Age (years) & $27(28)$ & $35(23)$ & 0.373 \\
\hline Male/female $(N)$ & $8 / 9$ & $19 / 33$ & 0.569 \\
\hline Body temperature $\left({ }^{\circ} \mathrm{C}\right)$ & $38.9(1)$ & $38.7(1.3)$ & 0.408 \\
\hline Pulse pressure $(\mathrm{mm}$ of $\mathrm{Hg})$ & $43(23)$ & $50(26)$ & 0.199 \\
\hline Heart rate (beats/min) & $86(40)$ & $101(28)$ & 0.33 \\
\hline Natremia $(\mathrm{mmol} / \mathrm{L})[135-145] \dagger$ & $135(5)$ & $137(3)$ & 0.194 \\
\hline Chloremia (mmol/L) [90-105] & $99(2)$ & $100(4)$ & $0.037 \ddagger$ \\
\hline Kaliemia $(\mathrm{mmol} / \mathrm{L})[3.5-4.5]$ & $3.8(0.5)$ & $3.9(0.5)$ & 0.75 \\
\hline $\mathrm{HCO}_{3}^{-}(\mathrm{mmol} / \mathrm{L})[22-30]$ & $24(4)$ & $24(4)$ & 0.873 \\
\hline Proteinemia $(g / L)[60-80]$ & $74(8)$ & $73(5)$ & 0.109 \\
\hline Hematocrit $(\%)[36-44]$ & $40(8)$ & $38(6)$ & 0.319 \\
\hline Hemoglobinemia $(\mathrm{g} / \mathrm{L})$ [105-135] & $138(18)$ & $132(23)$ & 0.139 \\
\hline Platelets $\left(\times 10^{9} / \mathrm{L}\right)[150-350]$ & $163(63.7)$ & $170(88)$ & 0.197 \\
\hline Polymorphonuclear cells $\left(\times 10^{9} / \mathrm{L}\right)[1.5-8.5]$ & $4.07(2.48)$ & $4.47(2.35)$ & 0.479 \\
\hline Lymphocytes $\left(\times 10^{9} / \mathrm{L}\right)[1-4]$ & $0.56(0.29)$ & $0.51(0.35)$ & 0.625 \\
\hline AST (U/L) [4-37] & $39(43)$ & $26.5(24)$ & 0.011 \$ \\
\hline $\operatorname{ALT}(\mathrm{U} / \mathrm{L})[4-50]$ & $20(24.3)$ & $18(20.5)$ & 0.136 \\
\hline CK (U/L) [20-170] & $347(460)$ & $116(101)$ & $0.008 \ddagger$ \\
\hline $\mathrm{CRP}(\mathrm{mg} / \mathrm{L})[0-10]$ & $28.1(48.9)$ & $6.9(31.2)$ & 0.075 \\
\hline $\operatorname{APTT}(\mathrm{s})[25-40]$ & $37(4.5)$ & $37(3)$ & 0.218 \\
\hline Prothrombin level (\%) [70-100] & $71(12)$ & $73(18)$ & 0.492 \\
\hline Viral load $\left(\times 10^{3}\right.$ PFU equivalent $\left./ \mathrm{mL}\right)$ & $180(527) N=15$ & $5.3(38) N=44$ & $0.003 \ddagger$ \\
\hline Classic dengue fever $[N(\%)]$ & $11(64.7)$ & $45(86.5)$ & 0.071 \\
\hline DHF/DSS-like group $\$ N(\%)]$ & $1(5.8)$ & $3(5.8)$ & 1 \\
\hline Unusual manifestations $\mathbb{I}[N(\%)]$ & $5(29.4)$ & $4(7.7)$ & $0.035^{* *}$ \\
\hline Hospitalized $[N(\%)]$ & $6(35.3)$ & $17(32.8)$ & 1 \\
\hline
\end{tabular}

* Median value and $(25-75 \%$ interquartile range).

$\dagger$ Reference range is shown in brackets.

$\begin{aligned} & \dagger \\ & P\end{aligned}<0.05$, Mann-Whitney test.

$\S$ DHF/DSS-like group was defined as the presence of at least one of the following: internal hemorrhage, signs of plasma leakage, shock, platelet count $<50 \times 10^{9} / \mathrm{L}$.

II Unusual manifestations group was made up of other severe clinical manifestations not included in the definition of DHF/DSS-like group.

** $P<0.05$, Fisher test.

AST, aspartate aminotransferase; ALT, alanine aminotransferase; CK, creatine kinase; CRP, C reactive protein; APTT, activated partial thromboplastin time; PFU, plaque forming unit. 


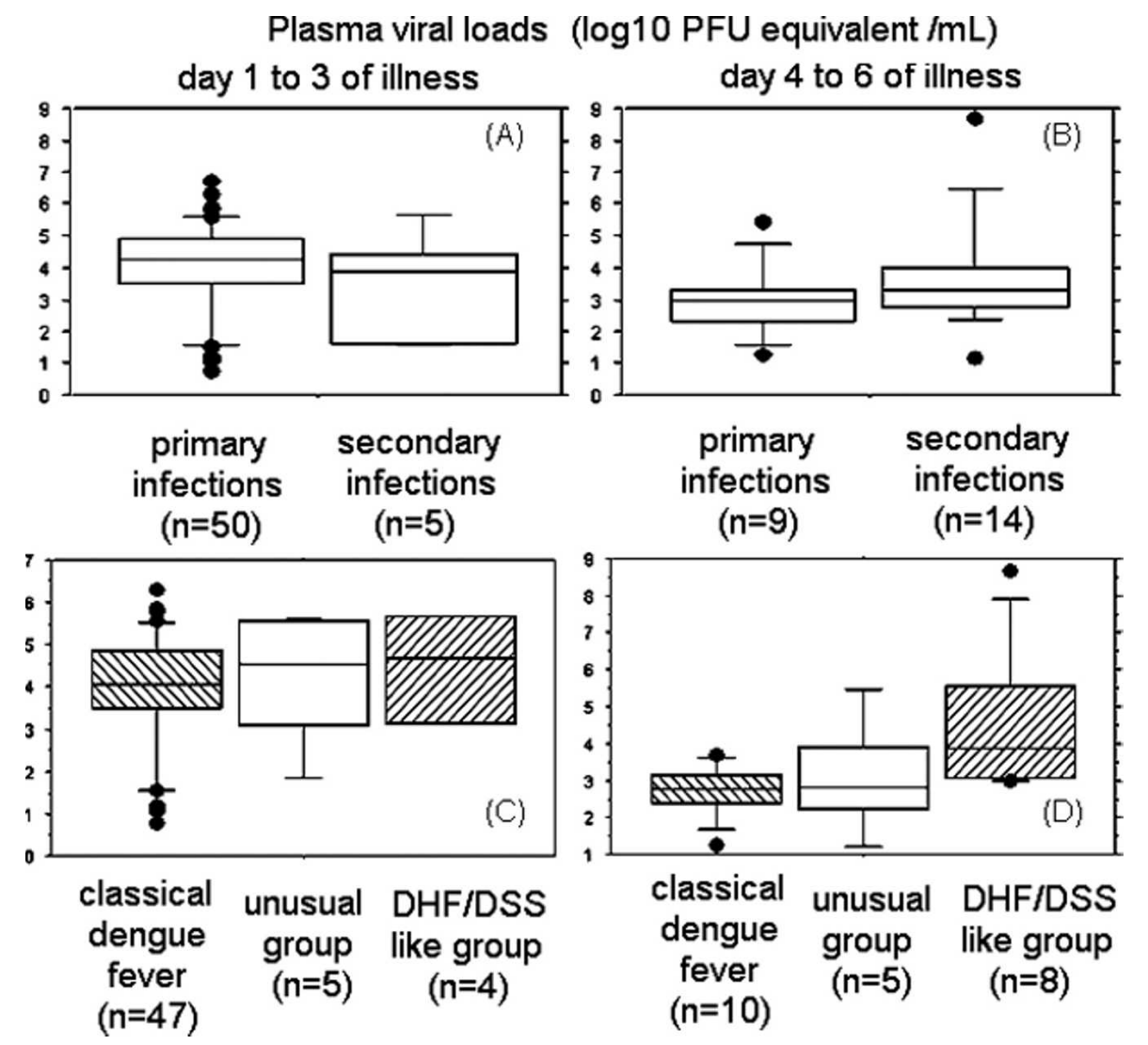

Figure 3. Distribution of plasma viral loads recorded in patients with dengue fever on admission to the emergency room. Left, Patients admitted within 3 days after onset of fever. Right, Patients admitted later. Box plots show median values (horizontal line in the box), 25-75\% interquartile range (lower-upper limits of the box), $90 \%$ range of data (additional bars), and outliers (circles). $N$, number of patients included. $\mathrm{A}, \mathrm{B}, \mathrm{C}$ No significant differences between groups; ${ }^{\mathrm{D}} P<0.05$, Kruskal-Wallis test. DHF/DSS-like group was defined as the presence of at least one of the following: internal hemorrhage, signs of plasma leakage, shock, platelet count $<50 \times 109 / \mathrm{L}$. Unusual group is made up of other severe clinical manifestations not included in the definition of DHF/DSS-like group.

tween primary and secondary infections (Table 2; Figure 3, A and B).

Relationship between the plasma viral load and the severity of disease. Presentation after the third day of illness was associated with higher viral loads in the DHF/DSS-like subgroup than in the other subgroups (Figure 3, C and D).

Multiple logistic regression analysis. Analysis was performed on data from patients with DENV-2 or DENV-4 and with primary or secondary dengue infections $(N=95$; Table 4). Analysis showed that unusual manifestations were independently associated with DENV-2 infection, whereas DHF/ DSS-like features were independently associated with a secondary immune response. Occurrence of gastrointestinal symptoms was associated with DENV-2 infection regardless of the immune status. Cough was associated with a secondary immune response regardless of the dengue virus serotype. Other symptoms such as body temperature, fatigue, postural hypotension, petechiae, or bleeding did not show any association. Syncope was associated with older age $(P=0.05$, Wald test). Increased hemoglobinemia, serum creatine kinase, and viremia levels were associated with DENV-2 infection. Increased serum liver enzymes levels, decreased platelet count, and increased activated partial thromboplastin time were associated with a secondary immune response. Decreased hematocrit and hemoglobinemia were associated with female sex $(P<0.001$, Wald test $)$. Some variables were asso- ciated with the time since onset of fever: platelets and polymorphonuclear cells counts and plasma viral loads decreased with time $(P<0.01$, Wald test $)$, whereas alanine aminotransferase, lymphocytes counts, and prothrombin levels increased with time $(P<0.01$, Wald test $)$.

\section{DISCUSSION}

This was a descriptive clinical study of a DENV-2 and DENV-4 co-epidemic in Martinique between June 2005 and April 2006. This study defines precisely which specific clinical features were associated with these serotypes. It corroborates previous findings from other studies but also points to a new finding that a cough is associated with secondary infection. Significant results of the study include increased severity of disease seen with DENV-2 and secondary infections.

The information in this study is based on laboratory methods that allowed comparison between DENV-2 and DENV-4 cases and between primary and secondary dengue infection cases. Because blood samples were collected during the acute phase of the disease, most of the dengue cases were RT-PCR positive, which permits genotyping. The 1:3 ratio of DENV-2 versus DENV-4 infections in patients attending the hospital was similar to that recorded by the general practitioner sentinel system, in which DENV-2 and DENV-4 accounted for 
TABLE 4

Clinical features and laboratory values independently associated with serotype and/or immune status in 95 patients diagnosed with DENV-2 or DENV-4 and primary or secondary dengue infections

\begin{tabular}{|c|c|c|}
\hline Dependent variables* & DENV-2 $(N=36 / 95)$ & Secondary dengue $(N=26 / 95)$ \\
\hline Gastrointestinal signs & $2.6[1-7.2](0.05)$ & $1.7[0.5-5.9](0.38)$ \\
\hline Cough & $0.6[0.2-2.1](0.43)$ & $11.7[2.5-55](0.002)$ \\
\hline Body temperature $>38.6^{\circ} \mathrm{C}$ & $2.1[0.7-6](0.19)$ & 0.6 [0.2-1.9] (0.34) \\
\hline Chloremia $<99 \mathrm{mmol} / \mathrm{L}$ & $0.4[0.1-1.1](0.07)$ & $0.8[0.2-3.1](0.79)$ \\
\hline Hemoglobinemia $>134 \mathrm{~g} / \mathrm{L}$ & $7.8[1.8-33.3](0.005)$ & $0.6[0.1-3.3](0.60)$ \\
\hline Hematocrit $>39 \%$ & $1.9[0.6-6.2](0.32)$ & $1.1[0.3-4.7](0.89)$ \\
\hline Platelet count $<100 \times 10^{9} / \mathrm{L}$ & $1.3[0.3-9.7](0.73)$ & $11.7[1.7-83.3](0.013)$ \\
\hline Lymphocytes $>0.63 \times 10^{9} / \mathrm{L}$ & $0.8[0.3-2.4](0.72)$ & $3.2[0.9-12](0.08)$ \\
\hline Polymorphonuclear cells $>3.96 \times 10^{9} / \mathrm{L}$ & $1.1[0.4-3.2](0.88)$ & $1.2[0.3-4.5](0.81)$ \\
\hline APTT $>38$ seconds & $2.3[0.8-6.5](0.12)$ & $4.8[1.3-17.9](0.018)$ \\
\hline Prothrombin level > 74\% & $0.4[0.1-13.7](0.12)$ & $1.7[0.4-6.3](0.46)$ \\
\hline $\mathrm{CK}>163 \mathrm{U} / \mathrm{L}$ & $4.5[1.3-15.6](0.018)$ & $1.5[0.3-6.9](0.64)$ \\
\hline $\mathrm{AST}>45 \mathrm{U} / \mathrm{L}$ & $2.5[0.8-7.6](0.11)$ & $12.2[2.9-52.6](<0.001)$ \\
\hline $\mathrm{ALT}>34 \mathrm{U} / \mathrm{L}$ & $1.4[0.5-4.3](0.56)$ & $5.7[1.4-22.8](0.013)$ \\
\hline Viral load > 7,160 PFU equivalent $/ \mathrm{mL}$ & $10[2.4-42.9](0.002)$ & $0.6[0.1-2.9](0.56)$ \\
\hline DHF/DSS-like group $\dagger$ & $1.7[0.4-8.1](0.49)$ & $10.7[1.7-67.5](0.012)$ \\
\hline Unusual manifestations group $\dagger$ & $4.5[1.2-17.2](0.029)$ & $1.2[0.3-6.1](0.78)$ \\
\hline
\end{tabular}

Values are adjusted ORs [95\% CIs] ( $P$ value). Adjusted odds ratios and $95 \%$ confidence intervals were obtained by means of multiple logistic regression analysis including the serotype and immune status as independent co-variables. Odds ratios were also adjusted for age, sex, and time since onset of fever. $P$ values were calculated by using the Wald test.

Values in bold indicate a significant independent association.

* Signs and symptoms and laboratory data were recorded on admission to the emergency room; continuous dependent variables were dichotomized around their median values, excepted for platelet count.

$\dagger$ Final classification of severity into DHF/DSS-like or unusual manifestations groups was based on data recorded during follow-up. DHF/DSS-like group was defined as the occurrence of at least one of the following: internal hemorrhage, signs of plasma leakage, shock, platelet count $<50 \times 10^{9} / \mathrm{L}$. Unusual manifestations group was made up of other severe clinical manifestations not included in the definition of DHF/DSS-like group.

APTT, activated partial thromboplastin time; CK, creatine kinase; AST, aspartate aminotransferase; ALT, alanine aminotransferase; PFU, plaque forming unit.

$28 \%$ and $70 \%$ of cases $(N=205)$, respectively. ${ }^{7}$ It must be noted that primary infection was more frequent at admission in DENV-4 than DENV-2 infection. DENV-2 has been most commonly detected in secondary infection in the Americas, ${ }^{6}$ whereas DENV-4 showed a more rapid geographic dispersal within the Caribbean basin. ${ }^{18}$ However, the important new information here is the occurrence of overt disease with both dengue 2 and 4 viruses during primary infections in adults. A scarcity of overt disease accompanying primary dengue 2 infections in adults was noted in the 1997 outbreak in Santiago, Cuba. ${ }^{19}$ In Thailand, primary dengue 2 and dengue 4 cases were rarely seen in hospital or out-patient pediatric populations. $^{20}$

Clinical data were recorded prospectively in the emergency room, but follow-up data were also taken into account when categorizing patients into the DF and DHF/DSS subgroups, as recommended by the WHO. ${ }^{1}$ Recent reviews have underlined the need to revise the dengue classification system. ${ }^{10,11}$ Phuong and others ${ }^{12}$ and Balmaseda and others ${ }^{14}$ suggested that dengue patients exhibiting at least one typical feature of DHF/DSS (i.e., internal hemorrhage, plasma leakage, marked thrombocytopenia, and/or shock) should be diagnosed with DHF/DSS. These authors also emphasized that sole use of the DHF/DSS classification to identify severe disease excludes a significant proportion of patients, and especially adults, with severe manifestations. This has been confirmed in a recent European study of dengue fever in travelers. ${ }^{21}$ Once classified on the basis of at least one of the principal criteria of DHF/ DSS, the patients showed characteristics usually seen with this form, including the duration of illness at initial presentation and its association with secondary dengue infection. In contrast, patients without signs of DHF/DSS but with other severe manifestations did not share these characteristics. Multivariate analysis showed that the association of DHF/DSSlike features with secondary dengue infection was independent of the serotype, whereas the association of unusual com- plications with DENV-2 was independent of the type of antibody response. These observations suggest that the classification proposed by Balmaseda and others ${ }^{14}$ is clinically relevant and may correspond to different pathophysiologic processes.

Among signs recorded in the emergency room, rash was certainly under-reported. ${ }^{3}$ This could be because of several factors including the time since clinical onset (most patients were examined at the acute febrile phase of illness) and the difficulty in observing this sign in patients mostly of mixed African ancestry. Gastrointestinal signs were reported in $\sim 50 \%$ of patients and were more frequently observed in DENV-2 infections. Symptoms such as nausea, abdominal pain, and vomiting are frequently reported. ${ }^{1,3}$ Sudden occurrence of an acute abdominal pain in patients with dengue fever should be considered as a sign of severity, particularly in children. ${ }^{3,12,13}$ Cough was observed in $25 \%$ of patients. It was the only clinical sign strongly associated with secondary immune response, independently from virus serotype and time since clinical onset. Because cough could be an early clinical sign of pleural effusion or pulmonary capillary leakage, we suggest that it should be considered as an indicator of potential severity.

Our data showed that the unusual manifestations occurred earlier than DHF/DSS-like features during the course of fever. However, some clinical features showed considerable overlap between the groups. Higher serum creatine kinase levels were mostly observed in primary DENV-2 infection. Rhabdomyolysis is not well described as a complication of dengue and is probably under-reported in the medical literature. ${ }^{22}$ Higher liver enzyme levels were associated with secondary infections, independently from virus serotype. Interestingly, a significant correlation was shown between plasma viral loads and liver enzymes levels, and it is noteworthy that the patient with DENV-2-associated fulminant hepatitis had the highest viral load. These findings are in agreement with 
previous publications suggesting that increased liver enzyme levels are strong predictors of severe clinical forms of dengue fever. ${ }^{23,24}$ Fulminant hepatitis is well documented in dengue infection and may result from a direct viral cytolysis or an adverse consequence of host immune response. ${ }^{25}$ It has been suggested that hepatic injury may relate more to viral factors, whereas vascular permeability may be mediated predominantly by the immune response. ${ }^{3}$ However, because most dengue patients are given paracetamol, the potential hepatic toxicity of this molecule should always be considered in dengue patients with increased liver enzymes levels.

Thrombocytopenia and coagulation disorders have been shown in severe dengue together with alterations of endothelial cells. ${ }^{26}$ Prolongation of partial thromboplastin time was shown in our patients diagnosed with secondary immune response. In most patients, this was not associated with significant alteration in other coagulation factor levels. Thrombocytopenia was associated with secondary immune response but also decreased significantly with time, the lowest platelet counts being recorded between 4 and 7 days after onset of fever. However, some patients were diagnosed with severe thrombocytopenia without other signs and symptoms of severe illness. Identification of clinical indicators of disease severity, and redefinition of the threshold for thrombocytopenia, should be evaluated by a large multicenter descriptive study. ${ }^{10,11}$

DENV-2 was associated with unusual complications, regardless of immune status, which might be partly ascribed to virulence. We confirm the pathogenicity of the AsianAmerican DENV-2 subtype, which had previously been linked to dengue hemorrhagic fever in Cuba in $1981 .{ }^{27}$ All the fatal cases where the serotype was known were DENV-2 secondary infections with DHF and unusual manifestations. These findings suggest that the most severe cases of dengue resulted from the combined effects of DENV-2 virulence and immune priming. Earlier studies in Thailand showed that secondary infection caused by DENV-2 was associated with more cases of DHF than was DENV-4 secondary infection. ${ }^{20}$ It has been postulated that more efficient DENV-2 replication in primed hosts confers enhanced pathogenicity. ${ }^{28} \mathrm{Re}-$ ports on viral loads and disease severity are contradictory. ${ }^{3}$ Molecular studies reported viral loads of higher, ${ }^{29}$ equivalent, ${ }^{30}$ or lower ${ }^{31}$ magnitude in secondary dengue. DHF has been shown to be associated with higher plasma viremia. ${ }^{28,30,32}$ There was no difference in plasma viral loads recorded in our patients with primary or secondary infection nor between the DF, DHF/DSS-like, and unusual manifestations groups. However, when the analysis was restricted to patients presenting 4 days or more after the onset of symptoms, the DHF/DSS-like subgroup was found to have higher viral loads. This is consistent with the report by Wang and others, ${ }^{33}$ suggesting slower clearance of the virus and viruscontaining immune complexes in DHF patients. These findings highlight the importance of the time since clinical onset when evaluating the significance of the plasma viral load and suggest that "original antigenic sin" and a partially misdirected humoral immune response may delay the viral clearance and create a vicious circle leading to exaggerated T-cell responses and immunopathogenesis of DHF/DSS. ${ }^{34-36}$

The correlation between DHF and secondary dengue infection is stronger when multiple serotypes circulate..$^{3,6,37}$
However, no increase in dengue morbidity or mortality was observed during the successive DENV-2/DENV-4, DENV-1, and DENV-3 epidemics that occurred in Martinique 4 years apart. ${ }^{38}$ The lower rate of DHF/DSS in the Americas than in Asia is well established ${ }^{5,6}$ and may be partly caused by differences in genetic background ${ }^{39,40}$ and in the genetic-driven immune response. The search for a dengue resistance gene in black populations should be pursued in future. ${ }^{41}$

Received December 14, 2007. Accepted for publication March 6, 2008.

Acknowledgments: We thank the medical and nursing staff of the Emergency and General Medicine Departments and the Intensive Care Units of Fort-de-France University Hospital for their care of the patients; Sylvie Carmès, Jean Robert Longhi, Sarah Schmitt, Paul Henri Chauvin, Robert Vignes, Karine Guitteaud, Claude Ramialison, Ingrid Laudarin, Cedric Fagour, Emily Corp, and Jim Blackburn for help in collecting the data; and Bernard Bucher and Rudy Valentino (CHU de Fort-de-France, Martinique), Mary Warrell (University of Oxford, Oxford, UK), and Bridget Wills (Oxford University Clinical Research Unit, Ho Chi Minh City, Vietnam), who reviewed the manuscript.

Financial support: This study was supported by Centre Hospitalier Universitaire de Fort-de-France.

Authors' addresses: Laurent Thomas, Stéphane Kaidomar, and Victor Moravie, Service des Urgences, Centre Hospitalier Universitaire, 97200 Fort-de-France, Martinique, Tel: 596-5965-52150, Fax: 5965967-50733. Olivier Verlaeten, Jenny Martial, Fatiha Najioullah, and Raymond Césaire, Service de Virologie-Immunologie, Centre Hospitalier Universitaire, 97200 Fort-de-France, Martinique, Tel: 5965965-52411, Fax: 596-5967-53669. André Cabié, Service des Maladies Infectieuses et Tropicales, Centre Hospitalier Universitaire, 97200 Fort-de-France, Martinique, Tel : 596-5965-59613, Fax: 596-596752116. Yves Plumelle, Laboratoire Hématologie-Coagulation, Centre Hospitalier Universitaire, 97200 Fort-de-France, Martinique, Tel: 596-5965-52000, Fax: 596-5967-58419. Christiane Fonteau, Laboratoire de Biochimie, Centre Hospitalier Universitaire, 97200 Fort-deFrance, Martinique, Tel: 596-5965-52000, Fax: 596-5967-53189. Philippe Dussart, Centre National de Référence des Arbovirus, Institut Pasteur de la Guyane, 23 Avenue Pasteur, BP 6010, 97306 Cayenne cedex, French Guyana, Tel: 594-5942-92609, Fax: 594-5942-95809.

Reprint requests: Laurent Thomas, Service des Urgences, Centre Hospitalier Universitaire, 97200 Fort-de-France, Martinique. E-mail: laurent.thomas@chu-fortdefrance.fr.

\section{REFERENCES}

1. World Health Organization, 1997. Dengue Haemorrhagic Fever: Diagnosis, Treatment, Prevention and Control. Second edition. Geneva: World Health Organization.

2. Halstead SB, 1988. Pathogenesis of dengue: challenges to molecular biology. Science 239: 476-481.

3. Gubler DJ, 1998. Dengue and dengue hemorrhagic fever. Clin Microbiol Rev 11: 480-496.

4. Rothman A, 2003. Immunology and immunopathogenesis of dengue disease. Adv Virus Res 60: 397-419.

5. Guzman MG, Kouri G, 2002. Dengue: an update. Lancet Infect Dis 2: 33-42.

6. Guzman MG, Kouri G, 2003. Dengue and dengue hemorrhagic fever in the Americas: lessons and challenges. J Clin Virol 27: $1-13$.

7. Anonymous, 2006. Situation épidémiologique de la dengue dans les Antilles Françaises. Bulletins d'Alertes et de Surveillance Antilles Guyane. Available at: http://www.martinique.sante 
.gouv.fr/documents/accueil/cire/basag2006-7.pdf. Accessed 7 November 2007.

8. Dussart P, Lavergne A, Lagathu G, Lacoste V, Martial J, Morvan J, Cesaire R, 2006. Reemergence of dengue virus type 4, French Antilles and French Guiana, 2004-2005. Emerg Infect Dis 12: 1748-1751.

9. Tolou H, Coussinier-Paris P, Mercier V, Pisano MR, de Lamballeie X, de Micco P, Durand J-P, 2000. Complete genomic sequence of a dengue type 2 virus from the French West Indies. Biochem Biophys Res Commun 277: 89-92.

10. Rigau-Perez JG, 2006. Severe dengue: the need for new case definitions. Lancet Infect Dis 6: 297-302.

11. Deen JL, Harris E, Wills B, Balmaseda A, Hammond SN, Rocha C, Dung NM, Hung NT, Hien TT, Farrar JJ, 2006. The WHO dengue classification and case definitions: time for a reassessment. Lancet 368: 170-173.

12. Phuong CXT, Nhan NT, Kneen R, Thuy PT, van Thien C, Nga NT, Thuy TT, Solomon T, Stepniewska K, Wills B, and the Dong Nai Study Group 2004. Clinical diagnosis and assessment of severity of confirmed dengue infections in Vietnamese children: is the World Health Organization classification system helpful? Am J Trop Med Hyg 70: 172-179.

13. Hammond SN, Balmaseda A, Pérez L, Tellez Y, Saborío SI, Mercado JC, Videa E, Rodriguez Y, Pérez MA, Cuadra R, Solano S, Rocha J, Idiaquez W, Gonzalez A, Harris E, 2005. Differences in dengue severity in infants, children, and adults in a 3-year hospital-based study in Nicaragua. Am J Trop Med Hyg 73: 1063-1070.

14. Balmaseda A, Hammond SN, Perez MA, Cuadra R, Solano S, Rocha J, Idiaquez W, Harris E, 2005. Short report: assessment of the World Health Organization scheme for classification of dengue severity in Nicaragua. Am J Trop Med Hyg 73: 10591062 .

15. Lanciotti RS, Calisher CH, Gubler DJ, Chang GJ, Vorndam AV, 1992. Rapid detection and typing of dengue viruses from clinical samples by using reverse transcriptase-polymerase chain reaction. J Clin Microbiol 30: 545-551.

16. Vaughn DW, Nisalak A, Solomon T, Kalayanarooj S, Nguyen MD, Keen R, Cuzzubbo A, Devine PL, 1999. Rapid serologic diagnosis of dengue virus infection using a commercial capture ELISA that distinguishes primary and secondary dengue infection. Am J Trop Med Hyg 60: 693-698.

17. Vazquez S, Hafner G, Ruiz D, Calzada N, Guzman MG, 2007. Evaluation of immunoglobulin $\mathrm{M}$ and $\mathrm{G}$ capture enzymelinked immunosorbent assay Panbio kits for diagnostic dengue infections. J Clin Virol 39: 194-198.

18. Carrington CV, Foster JE, Pybus OG, Bennett SN, Holmes EC, 2005. Invasion and maintenance of dengue virus type 2 and type 4 in the Americas. J Virol 79: 14680-14687.

19. Guzmán MG, Kouri G, Valdes L, Bravo J, Alvarez M, Vazques S, Delgado I, Halstead SB, 2000. Epidemiologic studies on dengue in Santiago de Cuba, 1997. Am J Epidemiol 152: 793799.

20. Nisalak A, Endy TP, Nimmannitya S, Kalayanarooj S, Thisayakom U, Scott RM, Burke DS, Hoke CH, Innis BL, Vaughn DW, 2003. Serotype-specific dengue virus circulation and dengue disease in Bangkok, Thailand from 1973 to 1999. Am J Trop Med Hyg 68: 191-202.

21. Wichmann O, Gascon J, Schunk M, Puente S, Siikamaki H, Gjørup I, Lopez-Velez R, Clerinx J, Peyerl-Hoffmann G, Sundøy A, Genton B, Kern P, Calleri G, de Gorgolas M, Mühlberger N, Jelinek T for the European Network on Surveillance of Imported Infectious Diseases, 2007. Severe dengue virus infection in travelers: risk factors and laboratory indicators. $J$ Infect Dis 195: 1089-1095.

22. Davis JS, Bourke P, 2004. Rhabdomyolysis associated with dengue virus infection. Clin Infect Dis 38: e109-e111.

23. Kalayanarooj S, Vaughn DW, Nimmannitya S, Green S, Suntayakom S, Kunentrasai N, Viramitrachai W, Ratanachu-eke S,
Kiatpolpoj S, Innis BL, Rothman AL, Nisalak A, Ennis FA, 1997. Early clinical and laboratory indicators of acute dengue illness. J Infect Dis 176: 313-321.

24. Murgue B, Deparis X, Chungue E, Cassar O, Roche C, 1999. Dengue: an evaluation of dengue severity in French Polynesia based on an analysis of 403 laboratory-confirmed cases. Trop Med Int Health 4: 765-773.

25. Ling LM, Wilder-Smith A, Leo YS, 2007. Fulminant hepatitis in dengue haemorrhagic fever. J Clin Virol 38: 265-268.

26. Krishnamurti C, Kalayanarooj S, Cutting MA, Peat RA, Rothwell SW, Reid TJ, Green S, Nisalak A, Endy TP, Vaughn DW, Nimmannitya S, Innis BL, 2001. Mechanisms of hemorrhage in dengue without circulatory collapse. Am J Trop Med Hyg 65: 840-847.

27. Guzman MG, Kouri GP, Bravo J, Soler M, Vazquez S, Morier L, 1990. Dengue hemorrhagic fever in Cuba, 1981: a retrospective seroepidemiologic study. Am J Trop Med Hyg 42: 179-184.

28. Vaughn DW, Green S, Kalayanarooj S, Innis BL, Nimmannitya S, Suntayakorn S, Endy TP, Raengsakulrach B, Rothman AL, Ennis FA, Nisalak A, 2000. Dengue viremia titer, antibody response pattern, and virus serotype correlate with disease severity. J Infect Dis 181: 2-9.

29. Kuberski T, Rosen L, Reed D, Mataika J, 1977. Clinical and laboratory observations on patients with primary and secondary dengue type 1 infections with hemorrhagic manifestations in Fiji. Am J Trop Med Hyg 26: 775-783.

30. Murgue B, Roche C, Chungue E, Deparis X, 2000. Prospective study of the duration and magnitude of viraemia in children hospitalised during the 1996-1997 dengue-2 outbreak in French Polynesia. J Med Virol 60: 432-438.

31. Yeh WT, Chen RF, Wang L, Liu JW, Shaio MF, Yang KD, 2006. Implications of previous subclinical dengue infection but not virus load in dengue hemorrhagic fever. FEMS Immunol Med Microbiol 48: 84-90.

32. Libraty DH, Endy TP, Houng HS, Green S, Kalayanarooj S, Suntayakorn S, Chansiriwongs W, Vaughn DW, Nisalak A, Ennis FA, Rothman AL, 2002. Differing influences of virus burden and immune activation on disease severity in secondary dengue-3 virus infections. $J$ Infect Dis 185: 1213-1221.

33. Wang WK, Chen HL, Yang CF, Hsieh SC, Juan CC, Chang SM, Yu CC, Lin LH, Huang JH, King CC, 2006. Slower rates of clearance of viral load and virus-containing immune complexes in patients with dengue hemorrhagic fever. Clin Infect Dis 43: $1023-1030$.

34. Mongkolsapaya J, Dejnirattisai W, Xu XN, Vasanowathana S, Tangthawornchaikul N, Chairunsri A, Sawasdivorn S, Duangchinda T, Dong T, Rowland-Jones S, Yenchitsomanus PT, McMichael A, Malasit P, Screaton G, 2003. Original antigenic sin and apoptosis in the pathogenesis of dengue hemorrhagic fever. Nat Med 9: 921-927.

35. Screaton G, Mongkolsapaya J, 2006. T cell responses and dengue haemorrhagic fever. Novartis Found Symp 277: 164-171.

36. Green S, Rothman A, 2006. Immunopathological mechanisms in dengue and dengue hemorrhagic fever. Curr Opin Infect Dis 19: 429-436.

37. Burke DS, Kliks S, 2006. Antibody-dependent enhancement in dengue virus infections. J Infect Dis 193: 601-603.

38. Cabie A, Strobel M, 2003. The clinical expression of dengue. Corriveau R, Philippon B, Yebakima A, eds. Dengue in Martinique, Guadeloupe and French Guiana. Paris: IRD Editions, 167-171.

39. Halstead SB, 2006. Dengue in the Americas and Southeast Asia: do they differ? Rev Panam Salud Publica 20: 407-415.

40. Sierra BL, Kouri G, Guzman MG, 2007. Race: a risk factor for dengue hemorrhagic fever. Arch Virol 152: 533-542.

41. Halstead SB, Streit TG, Lafontant JG, Putvatana R, Russell K, Sun W, Kanesa-Thasan N, Hayes CG, Watts DM, 2001. Haiti: absence of dengue hemorrhagic fever despite hyperendemic dengue virus transmission. Am J Trop Med Hyg 65: 180-183. 